\title{
28 Research Suare \\ A Population Based Study of Ocular Biometric Parameters in Colombia
}

Diana Cristina Palencia ( $\square$ disar1217@gmail.com )

Universidad Santo Tomas - Bucaramanga https://orcid.org/0000-0003-0915-3348

Martha Lucia Silva Mora

Saint Thomas University - Bucaramanga: Universidad de Santo Tomas - Bucaramanga

Melissa Julieth Ojeda Salazar

Saint Thomas University - Bucaramanga: Universidad de Santo Tomas - Bucaramanga

\section{Research Article}

Keywords: Myopia, Hyperopia, Astigmatism, Anterior Chamber, Axial length, Keratometry.

Posted Date: November 15th, 2021

DOI: https://doi.org/10.21203/rs.3.rs-1032818/v1

License: (1) This work is licensed under a Creative Commons Attribution 4.0 International License.

Read Full License 


\section{Abstract}

Introduction: The anthropomorphic parameters have influence on ocular biometric dimensions, so the characterization in a particular population is recommended. Parameters like axial length are important in the following of myopia and to predict the power of intraocular lens in cataract surgery.

Purpose: Describe ocular biometric parameters in the Colombian population: refractive condition, axial length (AL), anterior chamber depth (ACD) and keratometry.

Methodology: A Cross-sectional study of 3,334 people who living in urban and rural areas of nine departments in Colombia. Ages ranged from 8 to 56. In the selection process, probabilistic cluster sampling was used and to verify the selection criteria, participants were evaluated by general medicine and by optometry. Univariate and bivariate statistical analysis was carried out considering both the nature and the distribution of the variables.

Results. The $63.53 \%$ were women, and $54.32 \%$ resided in urban areas. The average age was 27.59 (Cl $95 \%$ to $95 \% 27.01-28.17$ ). Men reported a lower average age (24.43 years). Astigmatism and hyperopia were found to be more frequent in the refractive condition. When comparing AL by sex, slight differences are found and are statistically significant ( $P$ Value 0.00 ). A similar situation is evidenced in ACD ( $P$ Value $0.00)$.

Conclusions: It was revealed that there is a relationship between axial length and sex, area of residence, refractive condition, depth of the anterior chamber and corneal curvature. Likewise, it was found that the axial length and depth of the anterior chamber is greater in men than in women.

\section{Introduction}

The refractive condition is determined by the relationship between the power of two lenses (the cornea and the crystalline lens) and the axial length, which determine the focal point of light rays on the retina. ${ }^{1}$ In this regard, population-based studies show that eyeball dimensions may vary according to anthropometric characteristics. It has also been shown that large people tend to have greater axial length, a deeper anterior chamber, thinner lenses and flatter corneas. ${ }^{2}$ These facts, along with environmental factors and cultural habits, explain a large part of the differences in the prevalence reports of refractive errors.

Ametropia with the greatest change in axial length is myopia, the eye tends to be longer as evidenced in an investigation carried out with 255 eyes by the University of Shanghai's Department of Ophthalmology in which an axial length of $23.63 \mathrm{~mm}(+/-.92 \mathrm{~mm})$ was found in hyperopia, $24.62 \mathrm{~mm}(+/-.38 \mathrm{~mm})$ in emmetropia and $26.68 \mathrm{~mm}(+/-.75)$ in myopia. ${ }^{1}$ The reference values for axial length measurement from the anterior surface of the cornea to the foveola, range between 20 to $29.5 \mathrm{~mm}$ with an average of 24 $\mathrm{mm}$. This magnitude includes the depth of the anterior chamber whose mean value is usually $3.6 \mathrm{~mm}$ and in approximately $84 \%$ of people the values are between 3.2 to $4.0 \mathrm{~mm}^{3}$ 
In regard to cornea power, the standard values vary between +41.00 and +45.00 diopters, with an average of +42.75 diopters. The power of the lens has an average value of 20.35 diopters, and in $91 \%$ of eyes the diopter power of the lens oscillates between +18.00 and +23.00 diopters. ${ }^{4}$

The study of ocular biometric parameters is a key factor determining the refractive state, defining the power of the intraocular lens in cataract surgeries, and diagnosing early alterations such as posterior staphyloma, glaucoma, microphthalmos or nanophthalmos. ${ }^{3-5}$

Reference data on ocular biometric parameters is an important guide, but the recognition of multiple factors which can induce variations in these parameters has motivated population studies in Singapore, ${ }^{6}$ South and Central India, ${ }^{2}$ Alaska, ${ }^{7}$ Mongolia, ${ }^{8}$ California ${ }^{9}$ Australia, ${ }^{10}$ Myanmar, ${ }^{11}$ England, ${ }^{12}$ North and South China, ${ }^{13-16}$ Brazil, $^{17}$ Nigeria, ${ }^{18}$ Iran $^{19}$ Wisconsin, ${ }^{20}$ Jordan $^{21}$ and Korean. ${ }^{22}$ In the case of Colombia, there are no reference data, so the objective of this study was describe the refractive condition, axial length, anterior chamber depth, and keratometry in residents from nine departments of Colombia

\section{Methodology}

The investigation was endorsed by the Research and Ethics Committee of the Saint Thomas University, and all patients signed informed consent at the time of admission, and in the case of children between 7 and 17 years old the informed assent form was signed too. The ethical principles of beneficence, justice, non-maleficence and autonomy of the participants contemplated in the Declaration of Helsinki for biomedical research in human beings were respected.

\section{Selection of Participants:}

A cross-sectional study was carried out and included participants from urban and rural areas of nine Colombian departments (Santander, Cundinamarca, Bolívar, Caldas, Quindío, Tolima, Casanare, Cauca and Nariño).

People from 8 to 56 years who could recognize text or numbers were included, additionally, participants who used medications that affected accommodation such as: muscle relaxants, antihistamines, cycloplegics, cholinergics, antidepressants, morphine, marijuana, pilocarpine and alcohol were excluded. Also, were excluded people with pathological antecedents such as: diabetes, third nerve disease, degenerative diseases of the central nervous system, thyroid alterations, ocular pathological history of iridocyclitis, glaucoma, choroidal metastasis, Adie syndrome, the iris sphincter, ciliary body aplasia, Horner syndrome, trauma to the craniocervical region, lesions of the Edinger-Westphal nucleus, and patients with eccentric fixation.

\section{Sample size}

The sample size was calculated using the Epidat program with a confidence level of $95 \%$, a $1.5 \%$ precision, a 0.8 design effect, and an expected proportion of refractive errors of $30 \%{ }^{4}$ leaving 2869 
participants. Additionally, we adjust by $15 \%$ the non-response rate factored, so the final sample size was 3334 people.

\section{The sampling procedure}

A cluster sampling was used for the selection of participants. The urban areas and their metropolitan districts corresponded to the capital cities of each region, while the rural areas corresponded to those with a population of less than 5,000 inhabitants and were located more than $50 \mathrm{~km}$ from the urban area and at least 45 minutes from a local referral hospital.

Colombia is divided into 32 departments, in this study it was selected nine departments from four of five natural regions of the country. It was considering the population density of each department to define the proportion of the sample size in each place. In the departments, it was included a similar proportion of people from the principal city and the rural area around here. It was generated a list of volunteers based on which a random selection process was made to obtain the sample size.

\section{Data collection}

Age, sex, department, area of residence, refractive error, anterior chamber depth, axial length and keratometry were all evaluated. Consent and informed assent forms were initially completed and later the pre-selection form was completed to assess the selection criteria. The forms included personal data and antecedents, as well as a general medical examination to rule out pathologies that might affect the variables. Immediately, was evaluated the visual acuity with the optotype Bailey Lovie.

Refractive condition was evaluated with a retinoscope and a test box using the static retinoscopy technique. Radius curvature of the cornea measurement was done with the Helmholtz keratometer and both the depth of the anterior chamber and the axial length were determined by optical biometry (ALScan, NIDEK, LTD, Tokyo, Japan). Both keratometry and biometry were performed on two occasions and the average of the measurements was reported. Although both eyes in all the participants were evaluated, for the purposes of statistical analysis the right eye was randomly selected.

Optometric assessment was carried out by two trained optometrists, who used a standardized format for data collection and who also entered the information in duplicate in databases that were subsequently validated.

All the examinations were carried out in the communities in spaces provided by local authorities. In urban areas, evaluations were realized in health institutions. In rural areas, however, they were done in areas destined for educational, religious or social activities. Continuous calibrations were performed on the equipment used to ensure that the precision of the data was not affected by continuous movements.

\section{Statistical analysis}

Univariate and bivariate analysis was carried out in the software Stata 14, it was considering the nature and distribution of the data. For the qualitative variables, proportions were calculated. In the case of the 
quantitative variables, averages and confidence intervals were estimated. A stratified bivariate analysis was also performed considering categorized age and refractive condition.

Graphically, to show variations in the distribution of the data, boxplot graphs were constructed.

\section{Results}

Table 1 shows the characteristics of the population studied. The $63.53 \%(2,118)$ were women, this frequency is closed with the proportion of woman in the country (51.2\%) according to official report ${ }^{23}$. The $54.32 \%(1,811)$ resided in urban areas. The sample size was balanced by geographical area and those that reported the highest percentage of participation were Santander and Cesar with $14.49 \%$ (483), respectively. Participation by sex was also balanced in each of the departments. 
Table 1

Clinical and sociodemographic characterization of the study's population.

\begin{tabular}{|c|c|c|c|}
\hline VARIABLE & $\begin{array}{l}\text { TOTAL } \\
\mathrm{n}=3334\end{array}$ & $\begin{array}{l}\text { FEMALE } \\
\mathrm{n}=\mathbf{2 1 1 8}\end{array}$ & $\begin{array}{l}\text { MALE } \\
n=1216\end{array}$ \\
\hline Zone\% (n) & $54.32(1811)$ & $53.64(1136)$ & $55.51(675)$ \\
\hline Urban & $45.68(1523)$ & $46.36(982)$ & $44.49(541)$ \\
\hline \multicolumn{4}{|l|}{ Rural } \\
\hline \multicolumn{4}{|l|}{ Department \%(n) } \\
\hline Atlántico & $11.04(368)$ & $11.10(235)$ & $10.94(133)$ \\
\hline Caldas & $6.78(226)$ & $7.22(153)$ & $6.00(73)$ \\
\hline Casanare & $7.08(236)$ & $6.28(133)$ & $8.47(103)$ \\
\hline Cauca & $12.12(404)$ & $12.75(270)$ & $11.02(134)$ \\
\hline Cesar & $14.49(483)$ & $13.74(291)$ & $15.79(192)$ \\
\hline Nariño & $13.77(459)$ & $14.07(298)$ & $13.24(161)$ \\
\hline Quindío & $10.41(347)$ & $10.29(218)$ & $10.61(129)$ \\
\hline Santander & $14.49(483)$ & $14.35(304)$ & $14.72(179)$ \\
\hline Tolima & $9.84(328)$ & $10.20(216)$ & $9.21(112)$ \\
\hline Age & $27.59(27.01-28.17)^{a}$ & $29.40(28.68-30.12)$ & $24.43(23.49-25.38)$ \\
\hline \multicolumn{4}{|l|}{ Refractive error\%(n) } \\
\hline Astigmatism & $35.60(1187)$ & $37.49(794)$ & $32.32(393)$ \\
\hline Emmetropia & $24.60(820)$ & $21.20(449)$ & $30.51(371)$ \\
\hline Hyperopia & $35.09(1170)$ & $36.21(767)$ & $33.14(403)$ \\
\hline Myopia & $4.56(152)$ & $4.91(104)$ & $3.95(48)$ \\
\hline Not valued & $.15(5)$ & $.19(4)$ & $.08(1)$ \\
\hline Axial length & $23.13(23.10-23.17)$ & $22.92(22.88-22.96)$ & $23.49(23.43-23.54)$ \\
\hline Anterior chamber depth & $3.32(3.30-3.33)$ & $3.25(3.23-3.26)$ & $3.43(3.41-3.45)$ \\
\hline Keratometry & $43.08(43.02-43.13)$ & $43.37(43.30-43.43)$ & $42.57(42.49-42.66)$ \\
\hline Flat-K & $44.16(44.11-44.23)$ & $44.51(44.44-44.58)$ & $43.58(43.47-43.69)$ \\
\hline \multicolumn{4}{|l|}{ Steep- K } \\
\hline a. Mean $(95 \%$ & terval) & & \\
\hline
\end{tabular}


The average age of the population was 27.59 years (95\% $\mathrm{Cl} 27.01-28.17)$. Men, however, reported a lower average age ( 24.43 years). Regarding the refractive condition, astigmatism and hyperopia are the most frequent defects. In the case of axial length, when comparing it by sex, there are slight differences in the average that turn out to be statistically significant $(P$ Value $\leq .01)$ a similar situation occurs when evaluating the depth of the anterior chamber ( $P$ Value $\leq .01)$ (Table 1$).$

Table 2 shows that the axial length values are between $19.21 \mathrm{~mm}$ and $33.38 \mathrm{~mm}$. The lowest average value was recorded in myopic women from 8 to 10 years old (22.48 mm on average). The maximum axial length value was also found in women between $21-40$ years with an average of $28.45 \mathrm{~mm}$. Axial length was shorter after 40 years for men and women (Table 2). 
Table 2

Average axial length by ametropia

\begin{tabular}{|c|c|c|c|c|c|c|c|c|}
\hline \multirow[b]{2}{*}{ AGE } & \multicolumn{2}{|c|}{ EMMETROPIA } & \multicolumn{2}{|c|}{ ASTIGMATISM } & \multicolumn{2}{|c|}{ HYPEROPIA } & \multicolumn{2}{|c|}{ MYOPIA } \\
\hline & W & $M$ & W & $M$ & W & $M$ & W & $M$ \\
\hline & $\mathrm{n}: 449$ & $\mathrm{n}: 371$ & $\mathrm{n}: 794$ & n:393 & $\mathrm{n}: 767$ & $\mathrm{n}: 403$ & $\mathrm{n}: 104$ & $\mathrm{n}: 48$ \\
\hline & \multirow{2}{*}{$\begin{array}{l}22.8^{a} \\
(22.6- \\
23.1)\end{array}$} & \multirow{2}{*}{$\begin{array}{l}23.1 \\
(22.7- \\
23.4)\end{array}$} & \multirow{2}{*}{$\begin{array}{l}22.5(21.9- \\
23.1)\end{array}$} & \multirow{2}{*}{$\begin{array}{l}23.1 \\
(23.0- \\
23.3)\end{array}$} & \multirow{2}{*}{$\begin{array}{l}22.8 \\
(22.6- \\
23)\end{array}$} & \multirow{2}{*}{$\begin{array}{l}23.1 \\
(22.9- \\
23.3)\end{array}$} & \multirow{2}{*}{$\begin{array}{l}22.4 \\
(19.2- \\
25.6)\end{array}$} & \multirow{2}{*}{$\begin{array}{l}23.2 \\
(22.7- \\
23.7)\end{array}$} \\
\hline $\begin{array}{l}\text { years } \\
\text { n:336 }\end{array}$ & & & & & & & & \\
\hline $\mathrm{DS}^{\mathrm{d}}$ & .10 & .15 & .26 & .08 & .09 & .61 & .74 & .19 \\
\hline \multirow{2}{*}{$\begin{array}{l}11-20 \\
\text { years } \\
n: 1433\end{array}$} & 23.2 & 23.5 & 23.3 & 23.5 & 23.1 & 23.2 & 23.3 & 24.2 \\
\hline & $\begin{array}{l}(23.1- \\
23.3)\end{array}$ & $\begin{array}{l}(23.4- \\
23.6)\end{array}$ & $(23.1-23.6)$ & $\begin{array}{l}(23.4- \\
23.6)\end{array}$ & $\begin{array}{l}(22- \\
23.2)\end{array}$ & $\begin{array}{l}(23.2- \\
23.3)\end{array}$ & $\begin{array}{l}(22.7- \\
22.9)\end{array}$ & $\begin{array}{l}(23.7- \\
24.8)\end{array}$ \\
\hline $\mathrm{DS}^{\mathrm{d}}$ & .05 & .05 & .12 & .04 & .61 & .03 & .28 & .26 \\
\hline \multirow{2}{*}{$\begin{array}{l}21-40 \\
\text { years } \\
\text { n:346 }\end{array}$} & \multirow{2}{*}{$\begin{array}{l}23.1 \\
(22.8- \\
23.3)\end{array}$} & \multirow{2}{*}{$\begin{array}{l}23.7 \\
(23.1- \\
24.4)\end{array}$} & \multirow{2}{*}{$\begin{array}{l}23.6 \\
(22.9-24.2)\end{array}$} & \multirow{2}{*}{$\begin{array}{l}23.8 \\
(23.5- \\
24.2)\end{array}$} & \multirow{2}{*}{$\begin{array}{l}22.9 \\
(22.7- \\
23)\end{array}$} & \multirow{2}{*}{$\begin{array}{l}23.4 \\
(23- \\
23.8)\end{array}$} & \multirow{2}{*}{$\begin{array}{l}28.4 \\
(28.1- \\
29)\end{array}$} & \multirow{2}{*}{$\begin{array}{l}26.0 \\
(22.2- \\
29.8)\end{array}$} \\
\hline & & & & & & & & \\
\hline $\mathrm{DS}^{\mathrm{d}}$ & .12 & .30 & .30 & .16 & .10 & .16 & 4.92 & 1.48 \\
\hline$>40$ & 23.1 & 23.5 & 23.0 & 23.5 & 23.0 & 23.2 & 23.3 & 24.2 \\
\hline $\begin{array}{l}\text { Years } \\
\mathrm{n}: 1207\end{array}$ & $\begin{array}{l}(22.9- \\
23.3)\end{array}$ & $\begin{array}{l}(23.4- \\
23.6)\end{array}$ & $(22.6-23.4)$ & $\begin{array}{l}(23.4- \\
23.6)\end{array}$ & $\begin{array}{l}(22.9- \\
23)\end{array}$ & $\begin{array}{l}(23.2- \\
23.3)\end{array}$ & $\begin{array}{l}(22.6- \\
24.1)\end{array}$ & $\begin{array}{l}(23.7- \\
24.8)\end{array}$ \\
\hline$D^{d}$ & .07 & .05 & .18 & .04 & .07 & .03 & .34 & .26 \\
\hline \multicolumn{9}{|c|}{ Note: Five patients without refractive diagnosis } \\
\hline a. Ave & mi & $(9$ & lence in & u & ans & and & d & \\
\hline
\end{tabular}

When comparing values of the depth of the anterior chamber due to refractive defect, a greater magnitude is evident in the emmetropes (3.38 mm with $95 \% \mathrm{Cl} 3.36-3.40)$. Statistically significant differences were found in the value of the depth of the chamber above when comparing emmetropia with each type of refractive error (Table 3). 
Table 3

Refractive defects and depth of the anterior chamber

\begin{tabular}{|c|c|c|c|}
\hline $\begin{array}{l}\text { Refractive } \\
\text { Defects }\end{array}$ & Total & Anterior chamber depth & $P$ value ${ }^{a}$ \\
\hline Emmetropia ${ }^{c}$ & $24.60(820)$ & $3.38(3.36-3.40)$ & \\
\hline Astigmatism & $35.60(1187)$ & $3.34(3.32-3.36)^{b}$ & 0.01 \\
\hline Hyperopia & 35.09 (1170) & $3.23(3.21-3.25)$ & 0.01 \\
\hline Myopía & $4.56(152)$ & $3.44(3.38-3.51)$ & 0.02 \\
\hline \multicolumn{4}{|c|}{ A. Student's t test } \\
\hline \multicolumn{4}{|c|}{ B. Average (95\% confidence interval) } \\
\hline C. Reference & ory & & \\
\hline
\end{tabular}

Figure 1 shows an average anterior chamber depth of $3.31 \mathrm{~mm}(95 \% \mathrm{Cl} 3-30-3.33)$ for urban areas and $3.32 \mathrm{~mm}(95 \% \mathrm{Cl} 3.30$ - 3.34) for rural areas. No statistically significant differences exist between these values (Value P .71).

Figure 2 shows an average axial length of $23.19 \mathrm{~mm}(95 \% \mathrm{Cl} 23.14-23.24)$ for urban areas and 23.06 $\mathrm{mm}(95 \% \mathrm{Cl} 23.01-23.11)$ in rural areas. These differences are statistically significant ( $\mathrm{P}$ value $\leq .01)$.

\section{Discussion}

The study covers a sample of 3,334 people residing in Colombian in the departments of Atlántico, Caldas, Casanare, Cauca, Cesar, Nariño, Quindío, Santander and Tolima, and it shows that there is a statistically significant influence of variables such as gender, area of residence (rural / urban), refractive condition, anterior chamber depth and corneal curvature over axial length of the eyeball.

The data show particularly that the mean axial length of the studied population is $23.13 \mathrm{~mm}$, similar to that reported for the Iranian population (mean axial length $23.14 \mathrm{~mm}$ ), ${ }^{24}$ but lower than the results of studies carried out in Port Harcourt in the state of Rivers, Nigeria (mean axial length $23.2 \mathrm{~mm}$ ), ${ }^{25}$ China $(23.25 \mathrm{~mm})^{26}(23.32 \mathrm{~mm}),{ }^{27}$ India $(23.28 \mathrm{~mm}),{ }^{28}$ Nigeria $(23.31 \mathrm{~mm}),{ }^{29}$ Saudi (mean AL $\left.23.48 \mathrm{~mm}\right),{ }^{30}$ in a Mexican population (mean AL $23.44 \mathrm{~mm})^{3}$ and in the systematic review carried out by de Hoffer et al $(23.43 \mathrm{~mm}) .{ }^{31}$ It is higher, however, than that reported in Gujrat India $(22.78 \mathrm{~mm})^{32}$ and the Sudan (23.09 $\mathrm{mm})^{33}$; even so, were carried out in population groups with different sample sizes and ages.

Additionally, when analyzing the relationship of axial length and sex, it was evidenced that men have a higher axial length than women $(23.29 \mathrm{~mm}$ VS $22.92 \mathrm{~mm}$ ). A similar finding is reported in studies carried out in the Mexican population, ${ }^{3}$ in a suburban Caucasian population residing in Australia aged 49 years 
or older $(23.76 \mathrm{~mm}$ Vs $23.19 \mathrm{~mm}),{ }^{34}$ in Saudi Arabia $(23.61 \mathrm{~mm}$ Vs $23.34 \mathrm{~mm}),{ }^{30}$ and in Nigeria, the latter showing a mean difference of $.70 \pm .10 \mathrm{~mm}(\mathrm{P} \leq .01) .{ }^{25}$ In the study by Hoffer and Savini that included different races, a higher AL for all races was also evidenced in men than in women (Westerners $23.77 \mathrm{~mm}$ Vs $23.23 \mathrm{~mm}$, Latinos $23.80 \mathrm{~mm}$ vs $23.33 \mathrm{~mm}$, Asian $24.00 \mathrm{~mm}$ vs $23.33 \mathrm{~mm}$, Middle East $23.42 \mathrm{~mm}$ vs $22.99 \mathrm{~mm}$, and Asian Indian $23.68 \mathrm{~mm}$ vs 23.23$).{ }^{31}$ This result is consistent with the hypothesis tested by various studies in which a relationship exists between the dimensions of the eyeball and anthropometric measurements. ${ }^{2}$

In Port Harcourt, Nigeria, the relationship between age and axial length was studied without considering the refractive condition. There was shown to be no statistically significant difference. A longer axial length was recorded in men aged 51 to 60 and in women between 41 and 50 after which a decrease in axial lengths was observed in both sexes. ${ }^{25}$ In Saudi Arabia, a shorter axial length was found in people over 40 years of age $(23.35 \mathrm{~mm}$ vs. 24.23$) .{ }^{30}$ In the present study, the refractive condition was considered, and it was evidenced that myopic women aged between 21 and 40 have a higher axial length $(28.45 \mathrm{~mm})$ than myopic men $(26.03 \mathrm{~mm})$ of the same age group.

In this regard, in a study with 152 participants carried out between 2010 and 2011 in West Bengal, India between 8 and 70 years, an average axial length for emmetropes of $23.26 \mathrm{~mm}( \pm .64)^{34}$ is reported. This result coincides with the data in the group of women from 11 to 20 years of age $23.23( \pm .05)$. In the case of myopic patients, an average of $25.31 \mathrm{~mm}( \pm 1.12)$ was recorded, which is close to results in the group from 21 to 40 years of age $26.03 \mathrm{~mm}( \pm 1.48)$. In hyperopes, the average axial length was $22.50( \pm 1.38)$, close to that registered in women between 21 and 40 years of age observed in the present study 22.94 ( \pm $.10)$.

Additionally, the anterior chamber depth was $3.32 \mathrm{~mm}$ higher than that reported in the studies of West Bengal, ${ }^{34}$ India $(2.97 \mathrm{~mm}),{ }^{28}$ Saudi Arabia $(3.10 \mathrm{~mm}),{ }^{30}$ Nigeria $(3.23 \mathrm{~mm}),{ }^{35}$ and that reported in the review by Hoffer and Savini $(3.09 \mathrm{~mm}){ }^{31}$ In the study carried out in a Nigerian population, it was also found that men tend to have a deeper anterior chamber than women, ${ }^{35}$ a finding that agrees with the results of the present study, since an anterior chamber depth of $3.43 \mathrm{~mm}$ was found in men and of $3.25 \mathrm{~mm}$ in women.

About keratometry, the average of the flattest $\mathrm{K}$ was 43.08 diopters, a flatter value than in the Saudi population 43.74 diopters ${ }^{30}$ and in the study by Hoffer and Savini 44.01 diopters. $^{31}$

On the other hand, with the participants of this research, the prevalence of astigmatism and hyperopia was $35.60 \%$ and $35.09 \%$, higher than in Mashhad, Iran since the prevalence of these two refractive errors in individuals $>15$ years of age was $25.64 \%$ and $34.21 \%,{ }^{36}$ while the proportion of myopia was $3.64 \%$ in individuals $\leq 15$ years of age, and for subjects $>15$ years old, it was $22.36 \%$. In the present study the frequency of myopia was $4.56 \%$. 
Finally, considering advantages of this research, the inclusion of an urban and rural population residing in a Latin American country should be emphasized. Also, to be highlighted is the fact that it involves a wide age range that include children, adolescents and young adults, age groups that do not normally correspond to a population commonly addressed in studies on ocular biometric parameters. As limitations we recognize, the variations in the physical conditions for the performance of the exams, and the failure to include information related to the level of education ${ }^{15}$ and anthropometric measurements.

\section{Conclusions}

The study provides information on ocular biometric parameters in the Colombian population and shows a statistically significant relationship between axial length and sociodemographic and clinical variables such as anterior chamber depth, refractive condition, and corneal curvature.

It was also determined that the axial length is longer in men than in women, with the exception of myopic women between 21 and 40 years of age who have a larger axial length than men. On the other hand, the anterior chamber is deeper in men than in women.

Regarding the refractive condition, astigmatism and hyperopia were the most prevalent defects in both men and women.

\section{Declarations}

Conflict of interest: The authors declare that they have no conflict of interest and have no proprietary interest in any of the materials mentioned in this article

Funding information: This study was supported by a Colombian government's agency: the Administrative Department of Science, Technology and Innovation (COLCIENCIAS). Contract number: 495-2013. Code number:651756933785.

\section{Acknowledgments}

This work was supported by COLCIENCIAS and research Department, Fundación Oftalmologica de Santander (FOSCAL)

\section{References}

1. Puell Marin MC (Jan 2006) Physiological optics: optical eye system and binocular visión. Universidad Complutense de Madrid, Madrid

2. Nangia V, Jonas JB, Matin A et al (2010) Body Height and Ocular Dimensions in the Adult Population in Rural Central India. The Central India Eye and Medical Study.Ger J Ophthalmol; 248

3. Barlatey MS, Koga-Nakamura W, Moreno-Londoño MV et al (2019) Axial Length Distribution and Factors Associated an an Adult Population from Mexico City.Rev Mex Oftalmol; 93 
4. Bhardwaj V (2013) Axial Length, Anterior Chamber Depth-A Study in Different Age Groups and Refractive Errors.J Clin Diagn Res;7

5. Vetrugno M, Cardascia N, Cardia L (2000) Anterior Chamber Depth Measured by Two Methods in Myopic and Hyperopic Phakic IOL Implant.Br J Ophthalmol;84

6. Wong TY, Foster PJ, Tielsch JM, Johnson GJ et al (2001) Variations in Ocular Biometry in an Adult Chinese Population in Singapore: The Tanjong Pagar Survey.Invest Ophthalmol Vis Sci; 42

7. Wojciechowski R, Congdon N, Anninger W, Teo Broman A, Age Gender, Biometry, Refractive Error, and the Anterior Chamber Angle Among Alaskan Eskimos. Ophthalmol2003;110.

8. Wickremasinghe S, Foster PJ, Uranchimeg D et al (2004) Ocular Biometry and Refraction in Mongolian Adults.Invest Ophthalmol Vis Sci; 45

9. Shufelt C, Fraser-Bell S, Ying-Lai M et al (2005) Refractive Error, Ocular Biometry, and Lens Opalescence in an Adult Population: The Los Angeles Latino Eye Study.Invest Ophthalmol Vis Sci;46

10. Ojaimi E, Rose KA, Morgan IG et al (2005) Distribution of Ocular Biometric Parameters and Refraction in a Population-Based Study of Australian Children.Invest Ophthalmol Vis Sci; 46

11. Wu HM, Gupta A, Newland HS et al (2007) Association between Stature, Ocular Biometry and Refraction in an Adult Population in Rural Myanmar: The Meiktila Eye Study.Clin Exp Ophthalmol; 35

12. Foster PJ, Broadway DC, Hayat S et al (2010) Refractive Error, Axial Length and Anterior Chamber Depth of the Eye in British Adults: the EPIC-Norfolk Eye Study.Br J Ophthalmol; 94

13. He M, Huang W, Li Y et al (2009) Refractive Error and Biometry in Older Chinese Adults: The Liwan Eye Study.Invest Ophthalmol Vis Sci; 50

14. Xu L, Li Y, Zheng Y, Jonas JB (2006) Associated Factors for Age Related Maculopathy in the Adult Population in China: The Beijing Eye Study.Br J Ophthalmol; 90

15. Wong TY, Foster PJ, Johnson GJ, Seah SK, Education (2002) Socioeconomic Status, and Ocular Dimensions in Chinese Adults: The Tanjong Pagar Survey.Br J Ophthalmol. ; 86

16. Feng CL, Yuan YZ, Yuan F et al (2015) Biometric Analysis of Adult Cataract Surgery Candidates in Shanghai, China. West Ind M J;66

17. Rodrigues FW, Vidal LC, Silva RE .Ocular Biometry, Mathematical Estimation and Spherical Variation After Facectomy

18. Rev Bras Oftalmol 2015;74

19. Gessesse GW, Debela AS, Anbesse DH (2020) Ocular Biometry and their Correlations with Ocular and Anthropometric Measurements Among Ethiopian Adults.Clin Ophthalmol. Oct;14

20. Hashemi H, Khabazkhoob M, Emamian MH et al (2015) Association between Refractive Errors and Ocular Biometry in Iranian Adults.J Ophthalmic Vis Res. ; 10

21. Kinori M, Wehrli S, Kassem IS et al (2017) Biometry Characteristics in Adults and Children with Marfan Syndrome: from the Marfan Eye Consortium of Chicago.Am J Ophthalmol. ; 177

22. Mallen EAH, Gammoh Y, Al-Bdour M, Sayegh FN (2005) Refractive Error and Ocular Biometry in Jordanian Adults.Ophthalmic Physiol Opt;25

Page 12/15 
23. Lee DW, Kim JM, Choi CY et al (Age-Related Changes of Ocular Parameters in Korean Subjects. Clin Ophthalmol 2010)

24. DANE (Departamento Administrativo Nacional de Estadística). National population Census (2018) [Review 10 Jun 2021]. Available at: https://www.dane.gov.co/index.php/estadisticas-portema/demografia-y-poblacion/censo-nacional-de-poblacion-y-vivenda-2018/cuantos-somos

25. Hashemi H, Khabazkhoob M, Miraftab M et al (2012) The Distribution of Axial Length, Anterior Chamber Depth, Lens Thickness, and Vitreous Chamber Depth in an Adult Population of Shahroud, Iran. BMC ophthalmol 12:50

26. Aprioku I, Ejimadu C (2019) Analysis of Ocular Axial Length And Anterior Chamber Depth in Port Harcourt,Nigeria. WJOVR;2

27. Yin G, Wang YX, Zheng ZY et al (2012) Ocular Axial Length and its Associations in Chinese: The Beijing Eye Study.PloS; 7

28. Huang Q, Huang Y, Luo Q, Fan W (2018) Ocular Biometric Characteristics of Cataract Patients in Western China.BMC ophthalmol; 18

29. Maggon R, Singh SK, Jha M et al (2019) Correlation between Ocular Axial Length and Anterior Chamber Depth and a Differential Analysis in Same-Sized Eyes.Kerala J Ophthalmol; 31

30. Jagun OA, Onabolu OO, Ajibode HA (2015) Normative Ocular Biometric Dimensions and its Variation in a Nigerian Population. West Afr J Med; 34

31. Bamahfouz AY, Zabeedi A, Alqahtani $N$ et al (2016) Distribution of Axial Length, Anterior Chamber Depth, and K Reading In Saudi Population.JIAR For Multidisciplinary; 3

32. Hoffer KJ, Savini G (2017) Effect of Gender and Race on Ocular Biometry.Int Ophthalmol Clin; 57

33. Radadia HC, Sapre AA, Joshiyara PP, et alA et al (2017). Analysis of Keratometry and Axial Length Distribution in Urban Population of Gujrat, India.Indian J Clin Exp Ophthalmol; 3

34. Albashir SI, Saleem M (2015) Normal Range Values of Ocular Axial Length in Adult Sudanese Population.Al-Basar Int J Ophthalmol; 3

35. Roy A, Kar M, Mandal D et al (2015) Variation of Axial Ocular Dimensions with Age, Sex, Height, BMIand Their Relation to Refractive Status.J Clin Diagn Res Jan; 9

36. Olurin O (1977) Anterior chamber depths of Nigerians.Ann Ophthalmol; 9

37. Ostadimoghaddam H, Fotouhi A, Hashemi H et al (2011) Prevalence of the Refractive Errors by Age and Gender: The Mashhad Eye Study of Iran.Clin Experiment Ophthalmol; 39

\section{Figures}




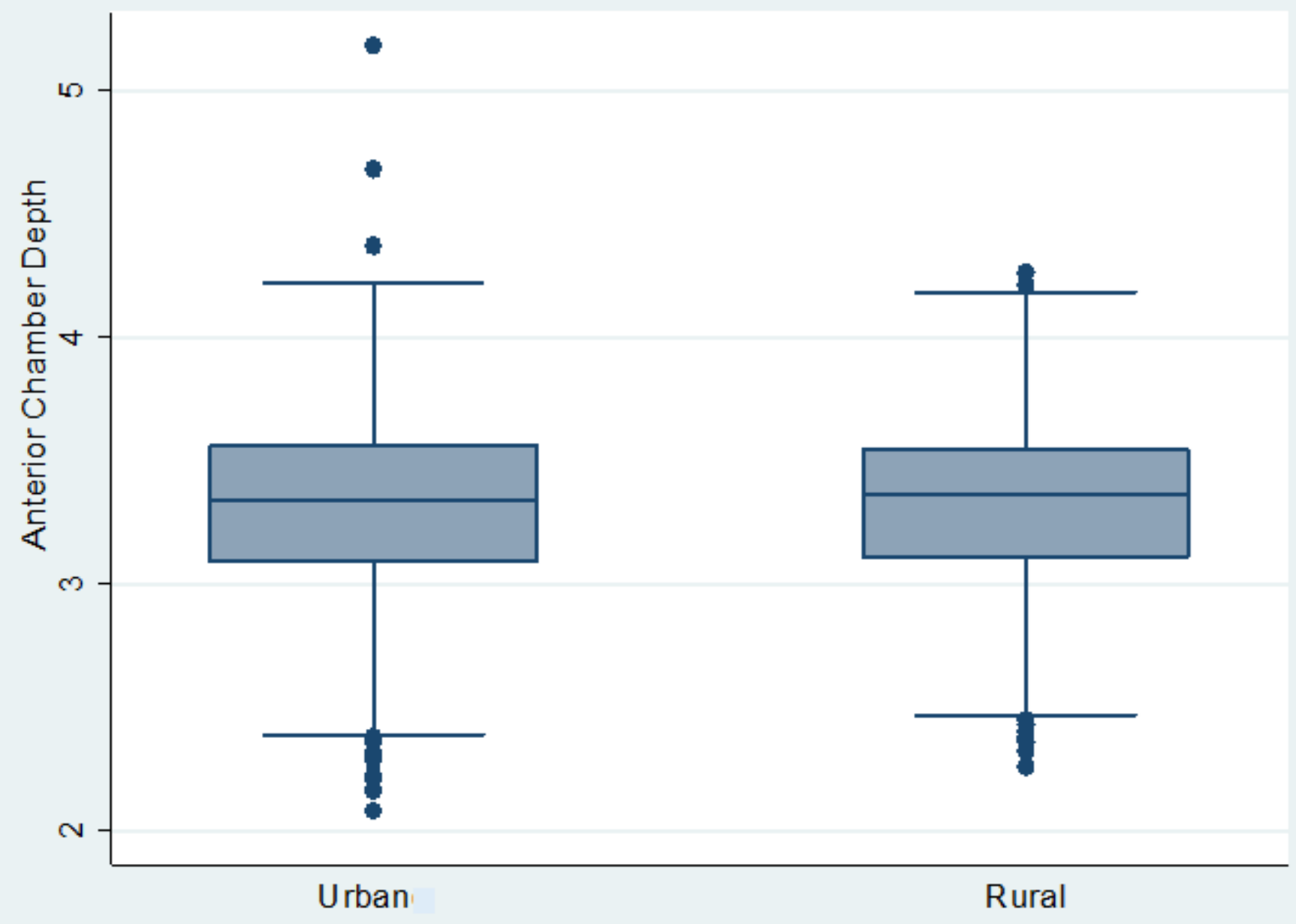

Figure 1

Box-plot diagram anterior chamber depth in urban and rural areas 


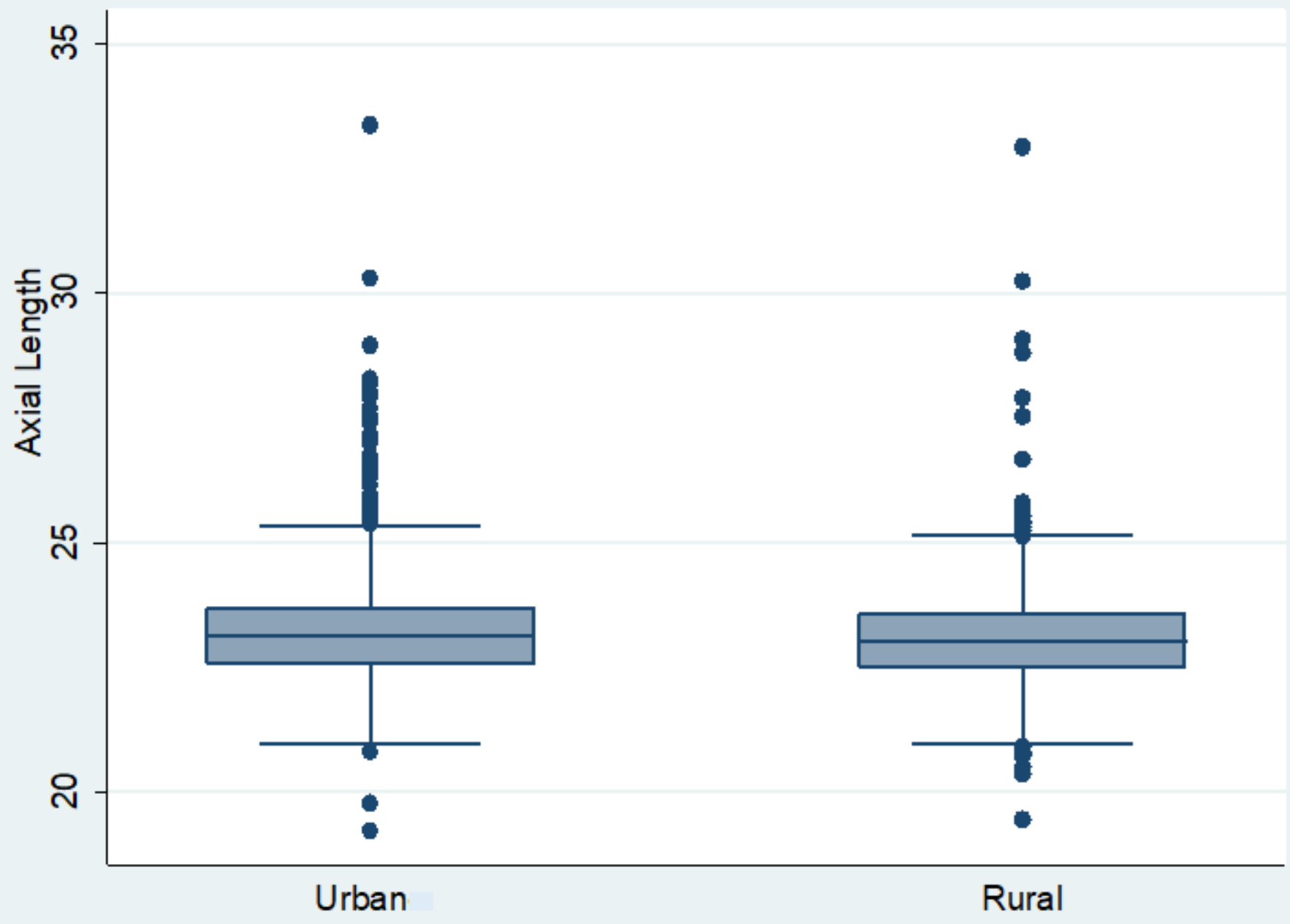

Figure 2

Box-plot diagram Axial Length in urban and rural areas 